\title{
Análise de Crescimento de Digitaria insularis ${ }^{1}$
}

\author{
Growth Analysis of Digitaria insularis \\ MACHADO, A.F.L. ${ }^{2}$, FERREIRA, L.R. ${ }^{3}$, FERREIRA, F.A. ${ }^{3}$, FIALHO, C.M.T. ${ }^{4}$, \\ TUFFI SANTOS, L.D. ${ }^{5}$ e MACHADO, M.S. ${ }^{4}$
}

\begin{abstract}
RESUMO - Digitaria insularis é uma espécie perene, que se reproduz por sementes e rizomas, sendo de difícil controle após a primeira floração. Visando definir técnicas para o manejo integrado dessa espécie, o seu crescimento foi avaliado em casa de vegetação, em recipiente plástico contendo $0,003 \mathrm{~m}^{3}$ de solo. Avaliações de altura, área foliar e massa seca foram realizadas em 15 épocas, entre 14 e 112 dias após a emergência (DAE), em intervalos regulares de sete dias. Foi utilizado o delineamento experimental inteiramente casualizado, com quatro repetições. As plantas foram fragmentadas em raiz + rizoma, colmo e folha. Posteriormente, determinou-se a área foliar e a massa seca das diferentes partes após secagem a $70^{\circ} \mathrm{C} \mathrm{em}$ estufa com ventilação forçada, até massa constante. Os valores máximos de área foliar e a massa seca foram atingidos aos 98 e 105 DAE, respectivamente. As folhas apresentaram maior participação no acúmulo de massa seca total, seguida por raízes+rizomas, até os 105 DAE. O acúmulo de massa seca de Digitaria insularis foi lento até 45 DAE. A partir dessa época, verificou-se rápido acúmulo de massa seca nas raízes, o que pode ser atribuído à formação dos rizomas. Os valores da taxa de crescimento relativo (TCR) foram decrescentes com o tempo, devido à maior alocação de fotoassimilados para estruturas formadas com o desenvolvimento da planta. Digitaria insularis apresenta crescimento lento até $45 \mathrm{DAE}$, sendo este rápido a partir dos 45 até os $105 \mathrm{DAE}$, sugerindo a possibilidade de bom controle cultural dessa espécie por culturas que tenham crescimento inicial rápido, grande área foliar e que cubram rapidamente o solo.
\end{abstract}

Palavras-chave: manejo, planta daninha, taxa de crescimento.

ABSTRACT - Digitaria insularis is a perennial species that reproduces from seeds and rhizomes, being difficult to control after its first flowering. In order to define integrated management techniques to this species, its growth was evaluated under greenhouse conditions, using a pot filled with $0.003 \mathrm{~m}^{3}$ of soil. Height, leaf area and dry matter evaluations were carried out between 14 and 112 days after emergence (DAE), every 7 days, at 15 different times. The experiment was arranged in a completely randomized block design, with four replications. The plant was fragmented into root+rhizome, stem and leaf. After drying at $70^{\circ} \mathrm{C}$, leaf area and dry matter were determined. Highest leaf area and dry matter values were verified at 98 and $105 \mathrm{DAE}$, respectively. Leaves showed higher participation in dry matter total accumulation followed by roots+rhizome, up to 105 DAE. Dry matter accumulation of Digitaria insularis slowed down up to $45 \mathrm{DAE}$, increasing due to rhizome formation. Relative growth rate values decreased along time due to higher photo assimilate accumulation. Digitaria insularis showed slow growth up to $45 \mathrm{DAE}$, increasing from 45 to $105 \mathrm{DAE}$, suggesting the possibility of good cultural control by crops that have fast initial growth and large leaf area, covering the soil rapidly.

Keywords: management, weed, growth rate.

Recebido para publicação em 9.3.2006 e na forma revisada em 10.11.2006.

Doutorando do Dep. de Fitotecnia, Universidade Federal de Viçosa - DFT/UFV, bolsista do CNPq, <aroldomachado@yahoo.com.br> 36570-000 Viçosa-MG; ${ }^{3}$ Prof. do Dep. de Fitotecnia - DFT/UFV; ${ }^{4}$ Graduando em Agronomia - UFV; ${ }^{5}$ Eng-Agr., Doutor em Fitotecnia - DFT/UFV. 


\section{INTRODUÇÃO}

Estudos de crescimento de plantas têm sido freqüentemente utilizados para o conhecimento da ecologia de diferentes espécies e para análise comparativa entre espécies daninhas e culturas (Dunan \& Zimdahl, 1991; Christoffoleti et al., 1997; Christoffoleti, 2001). As taxas de crescimento podem refletir a habilidade e a hierarquia competitiva das espécies na comunidade vegetal (Roush \& Radosevich, 1985), a magnitude da taxa de crescimento relativo (TCR) e o tipo de ambiente de origem das plantas daninhas (Grime \& Hunt, 1975).

É importante o estudo do comportamento biológico/ecológico das espécies daninhas, a fim de traçar estratégias de manejo para elas. Vários fatores influenciam a probabilidade de infestação de uma área, como adaptabilidade ecológica e prolificidade de indivíduos, longevidade e dormência das sementes e de outros propágulos, freqüência na utilização de herbicidas de único mecanismo de ação e sua persistência, eficácia do herbicida e métodos adicionais empregados no controle das espécies daninhas (Gressel \& Segel, 1990).

As diferentes espécies e cultivares de plantas apresentam capacidades distintas de competir com as plantas daninhas. Vigor vegetativo, área foliar e taxa de absorção de nutrientes nos estádios iniciais de crescimento são características altamente significativas relacionadas com habilidade competitiva (Kawano et al., 1974).

A análise de crescimento de comunidades vegetais é um dos primeiros passos na análise de produção primária, caracterizando-se, portanto, como o elo entre o simples registro de rendimento das culturas e a análise deste por meios fisiológicos. Por meio dessa análise podem-se conhecer adaptações ecológicas das plantas a novos ambientes, a competição intraespecífica, os efeitos de sistemas de manejo e a capacidade produtiva de diferentes genótipos (Rodrigues et al., 1995). Ademais, a análise de crescimento representa a referência inicial na análise de produção das espécies vegetais, e seu uso requer informações que podem ser obtidas sem a necessidade de equipamentos sofisticados.

O capim-amargoso (Digitaria insularis) é uma espécie perene, herbácea, entoucerada, ereta, rizomatosa, de colmos estriados, com 50 a $100 \mathrm{~cm}$ de altura (Kissmann \& Groth, 1997). Em observações a campo, em áreas onde há uso contínuo de glyphosate, tem-se constatado que plantas originárias de sementes, quando jovens, são controladas pelo herbicida; contudo, quando elas se desenvolvem e formam rizomas, seu controle é ineficiente.

Nesse contexto, objetivou-se estudar características do crescimento de Digitaria insularis, levando em consideração a importância que apresentam esses estudos para o conhecimento da ecologia dessa espécie.

\section{MATERIAL E MÉTODOS}

O experimento foi conduzido em casa de vegetação do Departamento de Fitotecnia da Universidade Federal de Viçosa, nos meses de abril a agosto de 2004.

Sementes de Digitaria insularis foram coletadas a campo e colocadas para germinar em bandejas plásticas contendo substrato orgânico "PLANT MAX". Quando as plântulas emergiram, sete dias após a semeadura, foram transplantadas para vasos plásticos com capacidade para $0,003 \mathrm{~m}^{3}$, contendo solo de textura argilosa previamente adubado com $10 \mathrm{~kg} \mathrm{~m}^{-3}$ de N-P-K na proporção de 8-28-16. As irrigações foram realizadas diariamente, mantendose o solo próximo a $80 \%$ da capacidade de campo. A cada 15 dias realizavam-se adubações, com 0,2 g por vaso do fertilizante "Ouro Verde" diluído em $100 \mathrm{~mL}$ de água.

Os tratamentos foram constituídos por épocas de coletas das plantas, realizadas em intervalos regulares de sete dias, dos 14 aos 112 DAE (dias após a emergência das plantas). O delineamento experimental foi o inteiramente casualizado, com 15 tratamentos e 4 repetições, sendo os vasos distribuídos aleatoriamente na casa de vegetação e suas posições alternadas semanalmente.

Após a medição de altura com régua milimetrada, as diferentes partes das plantas (raiz + rizomas, colmo e folhas) foram separadas. A área foliar foi obtida pelo medidor de área Li-cor Instruments (modelo LI 3100). Em seguida, a massa seca das diferentes partes foi obtida após secagem em estufa com ventilação forçada a $70{ }^{\circ} \mathrm{C}$, até massa constante. 
Com base nos resultados de área foliar e massa seca acumulada, foram determinadas para cada época de avaliação a taxa de crescimento relativo (TCR), taxa de assimilação líquida (TAL), razão de área foliar (RAF) e razão de peso foliar (RPF), seguindo fórmulas sugeridas por Benincasa (2003).

A TCR expressa o crescimento da planta em um intervalo de tempo, em relação à biomassa seca acumulada no início desse intervalo, sendo calculada pela fórmula: TCR $=\left(\ln \mathrm{P}_{\mathrm{n}}-\ln \mathrm{P}_{\mathrm{n}-1}\right) /\left(\mathrm{T}_{\mathrm{n}}-\mathrm{T}_{\mathrm{n}-1}\right)$, em que $\ln \mathrm{P}_{\mathrm{n}}$ é $\mathrm{o}$ logaritmo neperiano da biomassa seca acumulada até a avaliação $\mathrm{n}$; $\operatorname{lnP}_{\mathrm{n}-1}$ é o logaritmo neperiano da biomassa seca acumulada até a avaliação $\mathrm{n}-1 ; \mathrm{T}_{\mathrm{n}}$ é o número de dias após a emergência por ocasião da avaliação n; e $T_{n-1}$ é o número de dias após a emergência por ocasião da avaliação n-1 .

A TAL representa a taxa de fotossintese líquida e é determinada pela relação entre as biomassas secas produzidas por área foliar da planta, por um determinado intervalo de tempo, sendo calculada pela fórmula $\mathrm{TAL}=$ $\left.\left[\left(P_{n}-P_{n-1}\right) /\left(T_{n}-T_{n-1}\right)\right] .\left[\left(\ln A_{n}-\ln A_{n-1}\right) / A_{n}-A_{n-1}\right)\right], e m$ que $A_{n}$ é a área foliar da planta por ocasião da avaliação n; e $\mathrm{A}_{\mathrm{n}-1}$ é a área foliar da planta por ocasião da avaliação n-1.

A RAF representa a relação entre a área responsável pela realização de fotossíntese e a biomassa seca total produzida, sendo calculada pela fórmula $R A F=A_{n} / P_{n}$, em que $A_{n}$ é a área foliar da planta por ocasião da avaliação $n$ e $P_{n}$ é a biomassa seca acumulada até a avaliação n. A RPF representa a relação entre a biomassa seca das folhas e a biomassa seca total da planta, sendo calculada pela fórmula $\mathrm{RPF}=\mathrm{Pf}_{\mathrm{n}} / \mathrm{P}_{\mathrm{n}}$, em que $\mathrm{Pf}_{\mathrm{n}}$ é a biomassa seca das folhas por ocasião da avaliação $n$ e $P_{n}$ é a biomassa seca acumulada até a avaliação n.

Os dados obtidos foram submetidos à análise de regressão e o modelo foi escolhido levando-se em consideração a lógica do fenômeno biológico e o valor do coeficiente de determinação.

\section{RESULTADOS E DISCUSSÃO}

As plantas de Digitaria insularis apresentaram crescimento inicial lento até os 45 dias após o transplantio (DAT). Dos 45 aos $105 \mathrm{DAE}$ o crescimento foi acelerado e, após 105 dias da emergência, apresentou decréscimo acentuado, em decorrência da senescência foliar (Figura 1). O mesmo comportamento foi observado para raiz+rizoma, colmo e folha (Figura 1).

A emissão de inflorescências em $D$. insularis deu-se entre os 63 e 70 DAE. Apesar da grande quantidade de sementes formadas por planta, não foi de interesse separar a parte reprodutiva (inflorescência) das folhas. Portanto, as diferentes partes de Digitaria insularis estão representadas apenas por raízes+rizomas, colmos e folhas.

Na fase intermediária, o rápido incremento de massa seca das raízes a partir dos $45 \mathrm{DAE}$ se deve à formação dos rizomas (Figura 2), que são órgãos que apresentam, entre outras, a função de reserva; já a estabilização ao final do ciclo pode ser atribuída à redução da área foliar e à senescência da parte aérea.

O acúmulo máximo de massa seca total de D. insularis foi de 30,66 g por planta, valor inferior ao de outras espécies daninhas, como Senna obtusifolia (Erasmo et al., 1997), Commelina benghalensis (Rodrigues et al., 1995), Acanthospermum hispidium (Andreani Jr., 1995) e Hyptis suaveolens (Gravena et al., 2002), plantas do grupo $\mathrm{C}_{3}$. Esse menor acúmulo de massa seca, quando comparado ao de outras espécies, se deveu provavelmente às condições de temperatura e luminosidade baixa no período de condução do experimento.

Considerando a distribuição percentual da massa seca de Digitaria insularis ao longo do ciclo de crescimento, as folhas apresentaram maiores acúmulos em relação às demais partes das plantas, sendo responsáveis por valores entre 53\% do total acumulado pelas plantas no início do ciclo e 50\% no final do ciclo (Figura 3). Nesse mesmo período, as raízes+rizomas apresentaram acúmulos entre 47 e $20 \%$ no início e final do ciclo, respectivamente, quando as demais partes das plantas (colmo e folha) passaram a apresentar maior acúmulo de massa seca. O percentual de colmo apresentou valores entre 0\%, no início do ciclo, e 30\%, no final do ciclo de crescimento, ocorrendo inversão de acúmulo de massa seca com as raízes (Figura 3). Em Rottboelia exaltata (Bianco et al., 2004), Senna obtusifolia (Erasmo et al., 1997), 
Acanthospermum hispidum (Andreani Jr., 1995), Commelina benghalensis (Rodrigues et al., 1995), Cenchrus echinathus (Pavani, 1992) e Hyptis suaveolens (Gravena et al.,
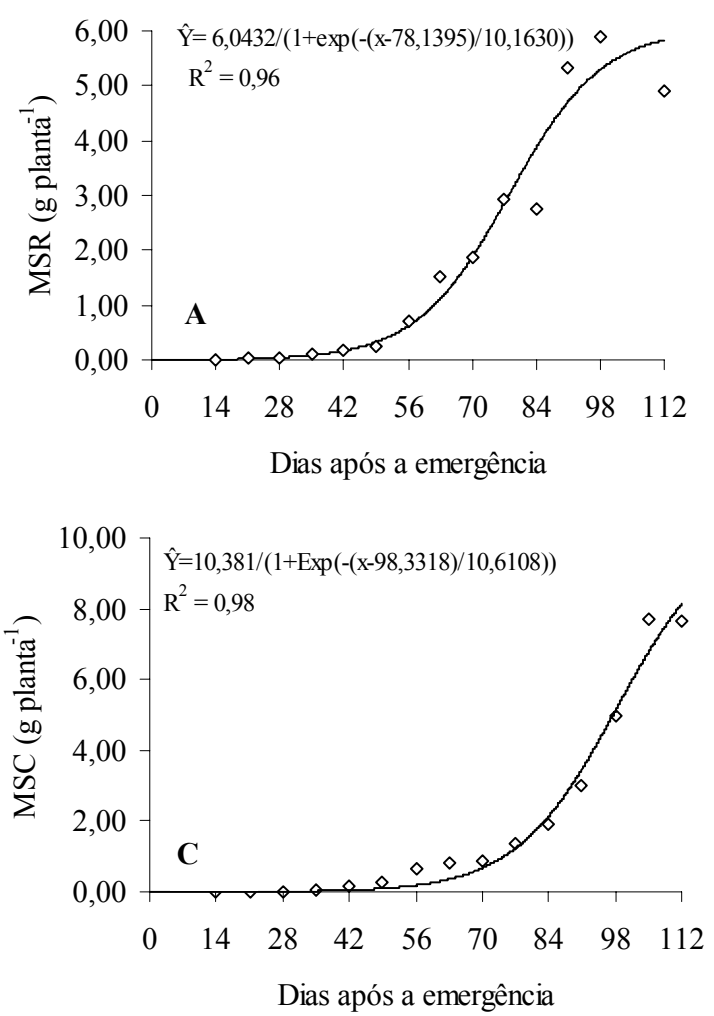

2002), com o crescimento das plantas, houve inversão da massa seca acumulada do colmo em relação à das folhas, o que não se verificou para $D$. insularis.
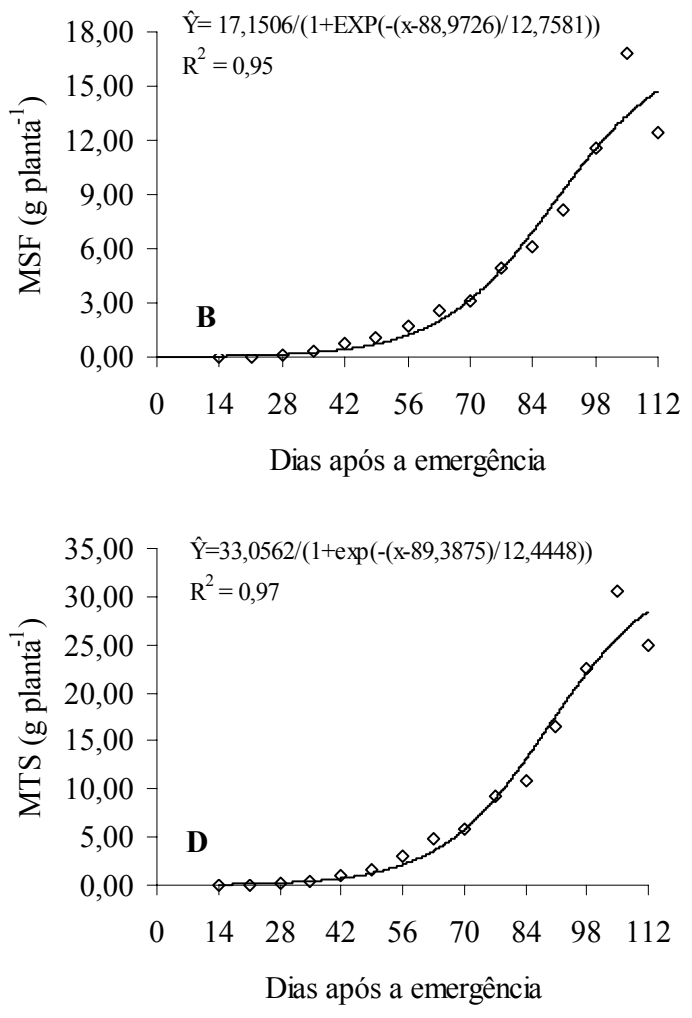

Figura 1 - Acúmulo de massa seca de Digitaria insularis ao longo de seu ciclo de desenvolvimento. A - raízes+rizomas (MSR); $\mathrm{B}$ - folha (MSF); C-colmo (MSC); e D - total (MTS).
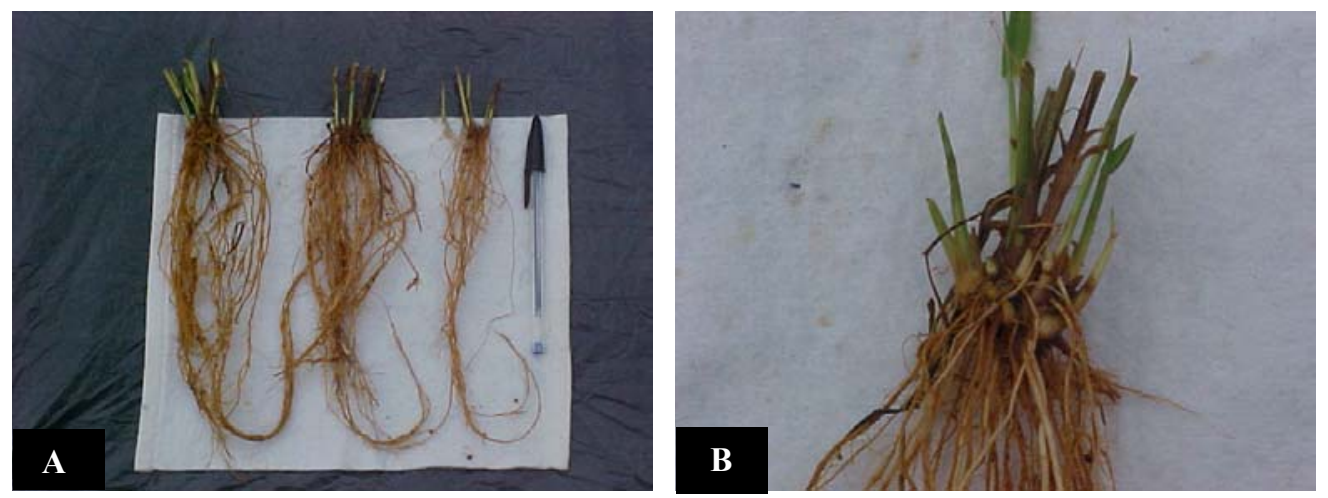

Figura 2 - Sistema radicular de plantas de Digitaria insularis aos 45 dias após a emergência. A - visão geral; e B - detalhes dos rizomas formados. 


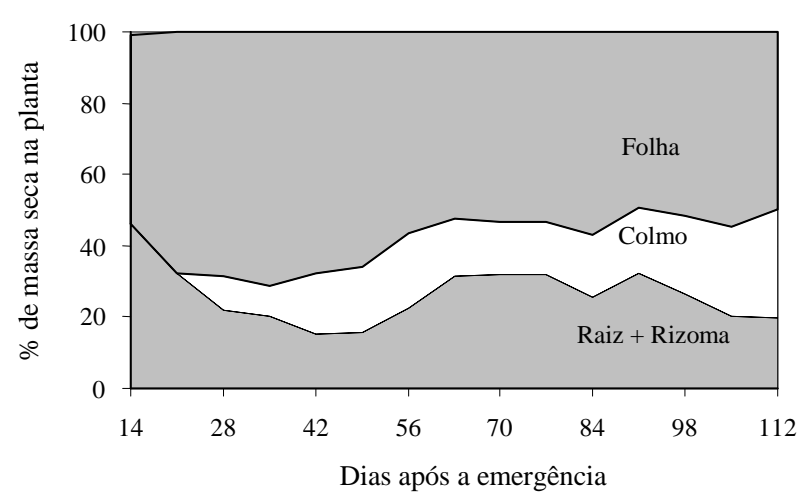

Figura 3 - Distribuição percentual de massa seca nas diferentes partes de plantas de Digitaria insularis ao longo do seu ciclo de crescimento.

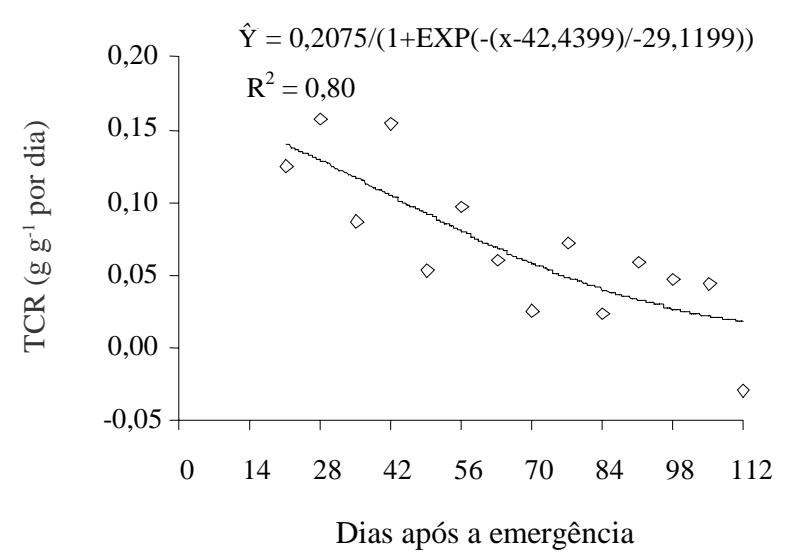

Figura 4 - Taxa de crescimento relativo (TCR) de Digitaria insularis ao longo do ciclo de crescimento.

Os valores da TCR foram decrescentes com o tempo, com média de $0,072 \mathrm{~g} \mathrm{~g}^{-1} \mathrm{dia}^{-1}$ quando considerada apenas a taxa positiva de crescimento (Figura 4). Esses valores foram inferiores aos obtidos por Erasmo et al. (1997) para Senna obtusifolia $\left(0,091 \mathrm{~g} \mathrm{~g}^{-1} \mathrm{dia}^{-1}\right)$ e superiores aos obtidos por Rodrigues et al. (1995), Andreani Jr. (1995) e Gravena et al. (2002) para Commelina benghalensis $\left(0,061 \mathrm{~g} \mathrm{~g}^{-1} \mathrm{dia}^{-1}\right)$, Acanthospermum hispidium $\left(0,059 \mathrm{~g} \mathrm{~g}^{-1} \mathrm{dia}^{-1}\right)$ e Hyptis suaveolens $\left(0,063 \mathrm{~g} \mathrm{~g}^{-1} \mathrm{dia}^{-1}\right)$, respectivamente. Com o aumento da massa seca acumulada pelas plantas, ocorre aumento na necessidade de fotoassimilados para a manutenção das estruturas já formadas; assim, a quantidade de fotoassimilados disponivel para o crescimento tende a ser menor e, conseqüentemente, a TCR é decrescente com o tempo (Benincasa, 2003).
A área foliar de $D$. insularis apresentou lento crescimento inicial até 45 DAE, que depois acelerou após o início da floração até 98 DAE (Figura 5); em seguida, iniciou-se o processo de senescência, ocorrendo perda das folhas e, conseqüentemente, redução na área foliar. O aumento na área foliar foi semelhante ao aumento na massa seca acumulada, com o ponto de inflexão da curva ocorrendo aos 98 DAE.

A razão de área foliar ( $\mathrm{RAF}$ ), a razão de peso de folha (RPF) e o total de massa seca acumulado pela planta foram decrescentes durante o crescimento desta. Esses resultados mostraram-se semelhantes aos observados em outras espécies daninhas e culturas (Pavani, 1992; Rodrigues et al., 1995; Erasmo et al., 1997; Gravena et al., 2002). A RAF e a RPF (Figura 5) apresentaram decréscimos acentuados do início até o final do ciclo. Dessa forma, os resultados indicam que, com o crescimento da planta, ocorre diminuição da área fotossintética útil e menor participação das folhas na massa seca acumulada. Considerando somente as taxas positivas, os valores médios obtidos para a RAF e a RPF foram de $56,39 \mathrm{~cm}^{-2} \mathrm{~g}^{-1} \mathrm{e}$ $0,74 \mathrm{~g} \mathrm{~g}^{-1}$, respectivamente.

A taxa de assimilação líquida (TAL) diminuiu com o tempo, indicando redução na capacidade fotossintética durante o ciclo, devido ao auto-sombreamento das folhas (Figura 5). A TAL média foi de 0,00129 $\mathrm{g} \mathrm{cm}^{-2} \mathrm{dia}^{-1}$, considerando-se somente as taxas positivas.

Assim como a massa seca acumulada pela planta, a RAF e a TAL podem ser correlacionadas com a capacidade competitiva das espécies daninhas (Roush \& Radosevich, 1985). Para a RAF, quanto maior o seu valor, menor é a competitividade da espécie, ao passo que para a TAL o comportamento é oposto. É importante destacar que, em diferentes condições de desenvolvimento, ou em condições naturais, outros atributos das plantas e a interação entre fatores ecológicos (bióticos ou abióticos) podem influenciar a capacidade competitiva das espécies (Roush \& Radosevich, 1985).

O lento crescimento inicial de $D$. insularis é uma característica que pode afetar na competição com outras espécies daninhas (Machado, 2005). Nesse sentido, no início de 

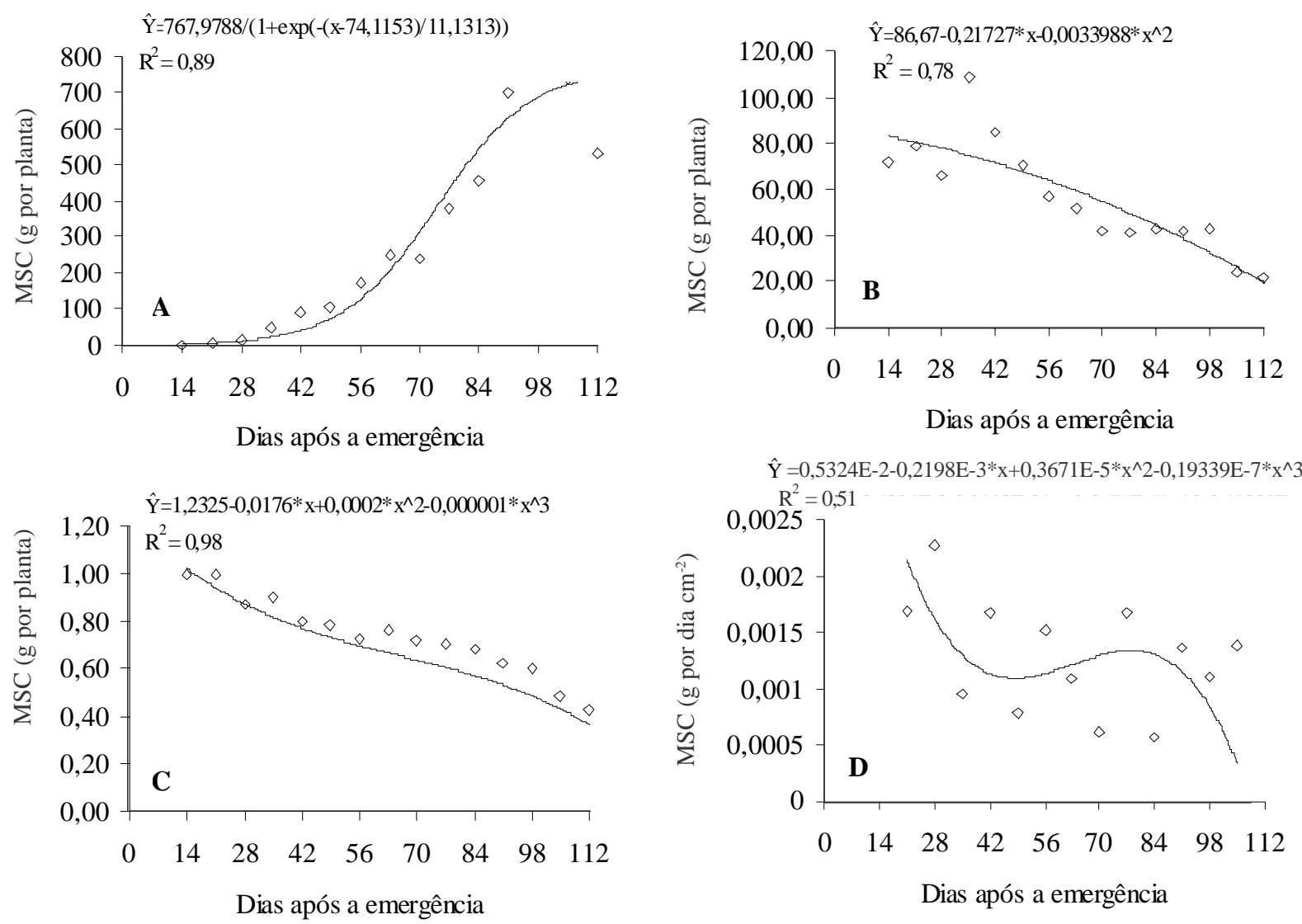

Figura 5 - A - área foliar (AF), B - razão de área foliar (RAF), C - razão de peso foliar (RPF) e D - taxa de assimilação líquida (TAL) de Digitaria insularis ao longo do ciclo de crescimento.

desenvolvimento, principalmente em condições de sombreamento ou de baixas temperaturas, por se tratar de uma planta tipo $\mathrm{C}_{4}$, as plantas de $D$. insularis podem ser suprimidas pelo desenvolvimento mais rápido de outras espécies da comunidade infestante. Por sua vez, se a dose do herbicida não for suficiente para controlá-la, ela pode se tornar uma espécie dominante, como acontece em muitos casos em lavouras de café e áreas de plantio direto, em que a dose de glyphosate é eficiente para outras espécies e insuficiente para o efetivo controle de $D$. insularis.

Dessa forma, o melhor período para controle de $D$. insularis é até os $35 \mathrm{DAE}$, quando os rizomas ainda não foram formados. Como essa espécie apresenta crescimento lento até 45 DAE, sugere-se a possibilidade de seu controle cultural satisfatório por culturas que cobrem rapidamente o solo.

\section{LITERATURA CITADA}

ANDREANI Jr., R. Estudo sobre dormência das sementes, o crescimento e absorção de macronutrientes por plantas de Acanthospermum hispidum. 1995. 72 f. Dissertação (Mestrado em Produção Vegetal) - Universidade Estadual Paulista, Jaboticabal, 1985.

BENINCASA, M. M. P. Análise de crescimento de plantas (Noções Básicas). Jaboticabal: FUNEP, 2003. 41 p.

BIANCO, S.; BARBOSA Jr., A. F.; PITTELI, R. A. Crescimento e nutrição mineral de capim-camalote. Planta Daninha, v. 22, n. 3, p. 375-380, 2004.

CHRISTOFFOLETI, P. J.; WEDTRA, P.; MOORE III, F. Growth analysis of sulfonylurea-resistant and susceptible kochia (Kochia scoparia). Weed Sci., v. 45. p. 691-695, 1997.

CHRISTOFFOLETI, P. J. Análise comparativa do crescimento de biótipos de picão-preto (Bidens pilosa) resistente e susceptível aos herbicidas inibidores de ALS. Planta Daninha, v. 19, n. 1, p. 75-84, 2001. 
DUNAN, C.; ZIMDAHL, R. L. Competitive ability of wild oats (Avena fatua) and spring barley (Hordeum vulgare). Weed Sci., v. 39, p. 558-563, 1991.

ERASMO, E. A. L.; BIANCO, S.; PITELLI, R. A. Estudo sobre o crescimento de fedegoso. Planta Daninha, v. 15, n. 2, p. 170-179, 1997.

GRAVENA, R. et al. Análise de crescimento de Hyptis suaveolens. Planta Daninha, v. 20, n. 2, p. 189-196, 2002.

GRESSEL, J.; SEGEL, L. A. Modeling the effectiveness of herbicide rotations and mixtures as strategies to delay or preclude resistence. Weed Technol., v. 4, p. 186-198, 1990.

GRIME, J. P.; HUNT, R. Relative growth-rate: its range and adaptive significance in local flora. Ecology, v. 63, n. 2, p. 393-422, 1975.

\section{KAWANO, K.; GONZALES, H.; LUCENA, M.}

Intraespecific competition, competition with weeds, and spacing response in rice. Crop Sci., v. 14, p. 841-845, 1974.
KISSMANN, K. G.; GROTH, D. Plantas infestantes e nocivas. São Paulo: BASF Brasileira, 1997. p. 675-678. Tomo I.

MACHADO, A.F.L. Biologia e controle químico de Digitaria insularis. 2005. 45 f. Dissertação (Mestrado em Fitotecnia) - Universidade Federal de Viçosa, Viçosa, 2005.

PAVANI, M. C. M. Estudo sobre o crescimento, nutrição mineral de Cenchrus echinathus L. e resposta a diferentes níveis de fósforo, pH e calagem. 1992. $110 \mathrm{f}$. Tese (Doutorado em Produção Vegetal) - Universidade Estadual Paulista, Jaboticabal, 1992.

RODRIGUES, B. N.; PITELLI, R. A.; BELLINGIERI, P. A. Efeito da calagem do solo sobre o crescimento inicial e absorção de macronutrientes em trapoeraba (Commelina benghalensis). Planta Daninha, v. 13, n. 2, p. 59-68, 1995.

ROUSH, M. L.; RADOSEVICH, S. R. Relationships between growth and competitiveness of four annual weeds. J. Appl. Ecol., v. 22, p. 895-905, 1985. 